ing with guinea-pigs, he was able to confirm Roux's finding with regard to the filtered juices, but could not do so regarding the filtered cultures. His results with the latter substances led him to conclude that the toxines from cultures were the reverse of protective. This is quite in accordance with the view that the products of the bacilli, acting like lactic acid, etc., help to overcome the resistance of an animal to black-quarter. I was proceeding in a similar, though slightly different manner. By means of a meat press I obtained the juices from the affected muscles of sheep. These juices were passed through a Chamberland filter, and then tried on guinea-pigs and sheep. The results of my experiments have been to confirm what Roux had already found in the guinea-pig, viz., that the muscle juices of animals dead from black-quarter are protective for other animals after filtration.

My object in undertaking the latter experiments was to see if it were possible to obtain a substance practically harmless to animals, but capable of enabling them to withstand such a dose of strong virus as would endow them with a higher degree of immunity than that acquired from the methods of preventive inoculation now practised. I have already pointed out that failures occur either because the vaccine is too strong or too weak. My reasons for using the muscle juice were, that it appeared to me to be the best way of getting an active toxin, and that one would get the benefit of any antitoxin substances that might be formed in the animal organism. If it were possible to get in the muscle juice such a protective substance as I have spolien of, one would have no hesitation in availing oneself of preventive inoculation even in districts where the death-rate from black-quarter is relatively very small. The amount of experimental evidence which I possess on this point is not sufficient as yet to justify a communication. So far, however, the results have been encouraging, and I hope at a future time to have the pleasure of communicating the outcome of some further experiments.

\title{
A FURTHER NOTE UPON MEDIAN NEURECTOMY.
}

By Fred. Hobday, F.R.C.V.S., Royal Veterinary College, London.

IN the Joumal of Comparative Pathology and Therapeutics for September I896, there was published an article upon "Median Neurectomy" in which was given a description of the method of operating and a summary of thirty-six cases in which the operation had been performed.

In the present article I propose to trace up as far as possible these cases, and to give an account of an additional fifty-one cases, making a total of eighty-seven individual animals (consecutive cases). The majority of them were patients in the Free Clinique of the College, and were operated upon by students of classes $C$ or $D$, the remainder being operated upon after consultation, and in conjunction with practioners in private practice.

It must be acknowledged that if the animals which have been operated upon have stood the test of time and been made 
useful for a prolonged period of work, "Median Neurectomy" may justly be considered amongst the operations which we should utilise for the relief of certain forms of lameness in the ordinary routine of daily practice. Particularly is this the case when the simplicity of the operation is considered.

In many of the cases operated upon all other known methods of treatment had previously been tried without success, and the only alternative course was slaughter.

Referring back to the cases recorded in the Journal for September I 896 the termination of Cases $1,5,6,7,10,17,23,25$, and 27 have been already mentioned.

CASE 2.-Cab mare operated upon I6th October I895, worked well and regularly until October I896, when she met with an accident and was killed.

CASE 3.-An aged cab mare, operated upon 29th October I895, worked regularly in the owner's possession until August 1896, when she was sold. The owner saw the animal at worlk for some time afterwards, but since then I have not been able to trace her.

CASE 4--A high stepping pony, six years old when operated upon on the I6th of November I 895 , is still working regularly and well, and has not been lame since. There is no alteration in the action, the pony stepping as well as ever.

CASE 8.-A carriage mare, about nine years old when operated upon on the 3 rd of February I 996 , has not suffered from lameness on that leg since, and is at present working regularly in a brougham.

CASE 9.-An aged cab mare, operated upon 5th February 1896 , is still working regularly and has not been lame on that leg since.

CASE I I.-A cab gelding, nine or ten years old when operated upon on the 29th of February I896, is still working regularly every day, and has not been lame on that leg since.

CASE 12.-A cart mare, six years old when operated upon on the I6th of March I896, is still working regularly and well. A large splint which was present under the knee is perceptibly diminished in size.

CASE 13.-An aged van gelding, operated upon on the i 8 th of March 1896 , is still working regularly and has not been lame on that leg since.

CASE 14.-An aged van gelding, operated upon on the 2 nd of April 1896 , in both fore legs, has been working regularly ever since.

CASE I 5.-A very old pony, operated upon on the 2nd of April I 896 , has been working regularly ever since.

CASE I6.-An aged cab mare, operated upon on both fore legs, 20th April i 896, has worked regularly without lameness ever since.

CASE I8. - A cab mare, aged, operated upon 25th April i 896. When publishing the account last year I had been unable to trace the case, but since then $I$ have seen the owner and find that the animal has been working regularly ever since.

CASE I9.-An aged cab mare, operated upon on the $27^{\text {th }}$ of April I 896 , is still working regularly and has shown no return of the lameness.

CASE 20.-An aged cart gelding, operated upon on the 29th of April 1896, is still working regularly and has shown no return of the lameness. 
CASE 21.-An aged cab gelding, operated upon on the 29th of April 1896 , has been working regularly in a hansom ever since.

CASE 22.- An aged cab gelding, operated upon on both fore legs, 29th May i896, was working regularly and well up to February i897. On the Igth of that month the animal was brought to the Clinique suffering from a wound of the off-fore coronet which appeared to be the result of a bruise or tread; on the $24^{\text {th }}$ this was going on well and had almost healed. The animal went to work again after this, but was eventually destroyed in June owing to a suppurating corn which terminated in quittor.

CASE 24.-An aged cab gelding, operated upon on the 15 th of June 1896 , worked regularly and well until December, when the animal fell lame again on the same leg, appearing in great pain and continually resting the leg. An examination of the seat of operation revealed excessive tenderness on pressure, and a distinct lump as large as a hazel nut apparently adherent to the fascia at the back of the radius. A neuroma was diagnosed and removed, after which the horse walked without lameness, and trotted almost sound at once. The wound progressed favourably, and everything promised well for a good recovery. Unfortunately, the animal bruised its elbow whilst standing in the stable, and as this suppurated and looked like being a prolonged case, the owner had the horse destroyed without my knowledge.

CASE 26.-A van mare, nine or ten years old when operated upon on the 22 nd of June $\mathrm{I} 896$, has been working regularly ever since.

CASE 28. - An aged cab mare, upon which median neurectomy was performed I 7 th July I896, and double plantar neurectomy 7 th August, worked regularly and well until i6th October, when the animal was condemned for farcy and destroyed.

CASE 29.-An aged cab gelding, operated upon on the i 7 th July I 896 , is still working regularly.

CASE 30.-An aged cab gelding, operated upon in both fore legs on the 29th July 1896, with the exception of about three weeks' rest worked regularly until June $\mathrm{I} 897$, when a fall in the street caused a fractured limb, for which the animal was destroyed. The three weeks' rest occurred in November and December and were due to lameness caused by very severe thrush involving the sensible structures of one fore foot; treatment was adopted and the animal returned to work as usual.

CASE 3I.-A cart gelding, operated upon (when seven years old) on the 29 th of July I 896 , showed decided improvement in the lameness when last seen (2 Ist October), but was still too lame for work. External plantar neurectomy for the relief of a ringbone, which had developed since the date of the median operation, was advised, but the owner would not give consent. The animal was turned out to grass for a while, after which the lameness completely passed off, and it is now working regularly. Once or twice it has shown lameness since on the same leg.

CASE 32.-A cab mare, operated upon (when eight or nine years old) on the roth of August I896, showed improvement after the operation. External plantar neurectomy was advised for the ringbone present, but the owner did not give consent, and since then I have not been able to trace the patient. 
CASE 33.-An aged trap gelding, which had median neurectomy performed I3th August I896, and external plantar neurectomy on the 28 th, improved sufficiently to go to walking or slow trotting work in September. The animal improved more at work, and has worked regularly ever since.

CASE 34.-An aged cab gelding, operated upon on the 2 Ist of August I896, was sent to work early in September, but I have been unable to trace it further.

CASE 35.-A pony gelding, six years old when operated upon on 2 ist August I 896 , did not show any immediate improvement after the operation, but early in September was sufficiently improved to be able to do walking work. Since then I have been unable to trace it.

CASE 36.-An aged cab mare, operated upon on the 26th of August I 896, is at present working in an omnibus. With the exception of a few weeks' rest, due to a wound (on the same leg) caused by the shaft of a cart, the animal has been working regularly ever since.

The above gives the history, as far as possible up to date, of the cases that were published last year in the September number of the Journal. The following are those which have been operated upon since :-

CASE 37--Cob, aged, very lame. Suffering from a large exostosis on the inside of the carpus. Before the operation was performed the owner was told that the lameness was probably partly mechanical owing to the situation of the bony growth.

Ioth September 1896 . Median neurectomy under chloroform. There was a decided improvement after the operation, and when the animal was seen a month later this improvement was maintained. Unfortunately I have been unable to trace the case further, and cannot say whether the animal ever became fit for regular work.

CASE 38.-Cart mare, rising six years old, suffering on the off foreleg from chronic tendinitis, a chain of splints inside the cannon bone, and a large exostosis on the knee, involving both the front and side. The tendons were thickened and contracted. This was the case operated upon before the members of the North of England Veterinary Medical Association. The mare had been lame for about ten months, and was fired and blistered without improvement three months ago. She could not do work without being lame for some days afterwards. The lameness was diagnosed as being partly due to the splints (as they were tender on pressure), and partly mechanical owing to the exostoses on the knee joint; the latter interfered with the joint so much that it could not be properly flexed.

2oth November i 896 . Median neurectomy under chloroform. Immediately after the operation there was a decided improvement; the wound healed well, and the animal was used for walking work until January I 897 , after which she gradually became lame again, and at present, $\mathrm{Mr}$ Elphick informs me, seems in much about the same condition as before the operation. The enlarged and stiffened condition of the knee joint is undoubtedly the chief cause of this, the lameness being mechanical.

CASE 39.-Cab mare, aged, had been very lame for about a month. The animal had a chain of splints under the tendons, chronic tendinitis, and ringbones. Lameness was diagnosed as being due to the chronic tendinitis and splints. 
I 8th November I896. Median neurectomy under chloroform. Lameness only very slight after operation. The wound progressed favourably, and the animal went to work early in December. There has been no return of the lameness, and the patient has worked regularly ever since.

CASE 40.--Light van mare, aged, had only been in owner's possession about three weeks, and had been very lame all the time. There was a very large splint, a sidebone and a ringbone on the inside of the leg, and a small ringbone on the outside. The splint was very sore on pressure, and lameness was diagnosed as being due to the irritation produced by this.

25th November I896. Median neurectomy under chloroform. No lameness could be perceived after the animal had trotted up and down a few times. This improvement was maintained, and the animal worked well for about a month, when it met with an accident in the street and was destroyed.

CASE 4I.-A light van gelding, aged, had been in the owner's possession about ten months, and been very lame a month. There was a large ringbone, a large splint, and chronic tendinitis. The lameness was diagnosed as due to the latter, and to the irritation produced by the splint.

26th November I896. Median neurectomy under chloroform. There was a perceptible improvement after the operation, but the animal never became sufficiently sound for the work required, and was sold at the end of two months; perhaps the ringbone may have been partly the cause.

CASE 42.- Cab mare, seven or eight years old, had been lame some weeks. Had ringbone and a large splint about the size of acob-nut under the tendon of the near fore leg. The splint was very tender on pressure, and had been severely punctured with the firing iron some time before. Lameness was diagnosed as being due to the presence of this splint.

3oth November 1896. Median neurectomy under chloroform. During the progress of the operation the student accidentally cut a collateral branch of the radial artery; this was ligatured and the operation completed. It was too dark to see whether the lameness had disappeared or not. The animal was seen again on the 9 th and I 5 th of December, and was decidedly better when walking, but showed lameness when trotting. The wound, however, was granulating freely, and had to be cauterised. Eventually she recovered and was worked by the owner for two months, but as she frequently caught the toe on the ground and stumbled he sold her for $£ 6$. Since then I have been unable to trace her.

CASE 43.--Pony, nine or ten years old, suffering from chronic tendinitis, contracted tendon, overshot fetlock, and ringbone. The animal was very lame both when trotting and walking, and had been so for three months.

30th November i 896. Median neurectomy was performed as a last resource. It was too dark to note progress immediately after the operation.

3oth December. The animal was sent to walking work, but was very lame when trotting.

2oth January I 897 . In order to make a further attempt to preserve 
the animal and make it fit for trotting work, external plantar neurectomy was performed. As, however, this did not have the desired effect the owner sold the animal, and since then I have been unable to trace it.

CASE 44.-A cab mare, aged, had had double plantar neurectomy performed on both fore legs for ringbones some nine months before. She had worked well until about a week ago, and was now suffering from very painful tumours on the ends of the divided nerves. As the legs were very puffy it was decided to try the effect of median neurectomy instead of dissecting out the tumours.

7 th December I 896 . Median neurectomy both fore legs. There was a decided improvement after the operation.

Ist January I897. No lameness. The wounds healed, but the owner had noticed a swelling in the off fore heel during the last week. On the I2th it was plain that gelatinous degeneration was taking place, and on the I 4 th the animal was destroyed.

CASE 45.-Cab horse, was suffering from navicular disease, and had had double plantar neurectomy performed on the 26th of October. At the present time the animal was suffering from lameness, especially noticeable at the commencement of a journey. There was also a large splint under the tendons, and the lameness was diagnosed as being due to this.

21st December I896. Median neurectomy under chloroform. Immediately after the operation there was a perceptible improvement, and on the 3 oth this was more marked. The animal was sent to work on the IIth of January, and has been working regularly since without lameness.

CASE 46.-A cab gelding, aged, had been lame off and on for eighteen months. The animal was suffering from a chain of large splints and ringbones on the near fore leg. Actual cautery was applied without any improvement five weeks before.

I 3 th January I 897 . Median neurectomy under chloroform. After the operation there was no lameness whatever, and since then the animal has worked regularly without any return of the intermittent symptoms.

CASE 47.-An aged pony, excessively lame on the near fore leg, due to the presence of a large splint under the tendons, and slight lameness on the near fore due to a chain of splints. The owner reported that the animal had been lame off and on for about six months.

I $3^{\text {th }}$ January I897. Median neurectomy on the off fore under chloroform.

I4th January. Median neurectomy on the near fore. After the two operations there was no lameness whatever.

28 th January. The wound was going on well, but the animal was exceedingly lame again.

6 th February. As on 28 th January, but the wound had now healed. Diagnosis of sprain of the pectoralis transversus muscle was made, and the parts thoroughly blistered. In about a fortnight afterwards recovery took place, and the animal worked regularly ever since until three weeks ago, when it fell lame from spavin on the near hind leg. This has been fired, and the animal is at present (September) out at grass.

CASE 48.-Aged pony, had been very lame on the off fore leg for 
two months, suffering from the effects of an exostosis as large as an average-sized orange on the inside and front of the knee.

I8th January I897. Median neurectomy under chloroform. Noticed peculiar rigors of the limb when the animal got up. Immediately after the operation there was no lameness when walking, and after trotting for about IOO yards no lameness could be perceived at that pace. The animal was sent to work about the Ioth of February, and since then has worked regularly without showing any lameness.

CASE 49.-An aged cab gelding, had been very lame off and on for six months on the off fore leg. Was suffering from a chain of splints and ringbones, both of which had been fired about three months before with temporary relief, but a full day's work always caused a return of the lameness.

I8th January I897. Median neurectomy under chloroform. When the animal stood up peculiar rigors of the limb were noticeable, as in Case 48. When walked and trotted there was no lameness. The horse was sent to work about the I Ith of February, but since then I have been unable to trace its progress.

CASE 50.-Cab mare, seven or eight years old, had been very lame for some months, was suffering from a chain of large splints and ringbones.

I9th January I897. Median neurectomy under chloroform. Immediately after the operation the lameness was scarcely perceptible. The animal was sent to work on the $14^{\text {th }}$ of February, and has been working regularly ever since.

CASE 5 I.-Cab mare, aged, very lame from a large exostosis on the inside of the fetlock joint; also had a splint and ringbones. A very bad case.

26th January I897. Median neurectomy under chloroform as a last resource. There was a slight improvement after the operation, but lameness was undoubtedly largely mechanical. I have been unable to trace this case further, so cannot definitely state whether the animal recovered sufficiently for walking work or was killed.

CASE 52.-A pony, seven years old when operated upon (3rd February I 897). The animal had been lame on and off for five months, and was suffering from a chain of small splints under the knee. These had been treated by several applications of blistering ointment without success. After the operation there was no lameness when walking, and when trotting it was only perceptible to an expert. The patient was sent to work at the end of February, and worked regularly for some time. Since then it has been sold and lost sight of.

CASE 53.-Aged cab gelding, suffering from intense lameness due to a large splint under the tendons of the near fore leg; the animal had been in the present owner's possession for four months, and had been lame off and on the whole time; ringbones were also present.

3rd February 1 897. Median neurectomy under chloroform. After the operation there was no lameness. When put to trotting work early in March the animal still showed lameness, and a smart blister was applied over the seat of operation. External plantar neurectomy was also advised, but the owner would not consent. The animal recovered sufficiently for walking work, and was sold; since then (June) it was kicked by another horse and sustained a fractured leg, for which it was destroyed. 
CASE 54--Cab mare, aged, has been lame four months, suffering from an exostosis inside the fetlock joint and ringbones. The actual cautery had been applied to the exostosis at the commencement of the lameness, but without benefit.

5 th February i 897 . Median neurectomy under chloroform.

I 5 th February. Still very lame; probably largely mechanical. Advised external plantar neurectomy, but the owner would not consent until the wound had healed completely.

igth February. Wound had healed, but was now granulating a little too freely. The lameness to-day was scarcely perceptible. The mare made a good recovery, and has been working regularly ever since.

CASE 55.-Cab mare, aged, had been in owner's possession two years, and had been lame on the near fore leg off and on for eighteen months. There was a large exostosis under the linee, an atrophied frog, and a concave sole. The lameness was diagnosed as being due to navicular disease, and the ordinary double plantar neurectomy was performed on the 8 th of February 1897 . This produced no improvement, so, thinking that the exostosis under the knee was probably a source of pain, the animal was again cast, and median neurectomy performed under chloroform. When trotted immediately after the operation there was no lameness. Owing to the upper wound not being kept clean a pocket of pus formed under the arm; this was lanced, and on 9th March, although the leg was still swollen and the wound discharging, there was but very slight lameness. The mare, however, never got sound enough for cab work, and was destroyed.

CASE 56.-Cab mare, been very lame about two months, suffering from a large splint and side bone on the inșide of the leg, and a thickening on the inside of the fetlock joint.

Ioth February I 897. Median neurectomy under chloroform. After the operation the lameness was scarcely perceptible. The wound healed well, but about three weeks afterwards the mare bruised her knee very severely in the stable. This suppurated and burst, leaving a very nasty ulcerating and excessively granulating wound on the front of the joint. This was successfully treated, and the animal sent to work about I2th April. Since then there has been no return of the lameness, and the animal has worked regularly.

CASE 57.-Cab mare, aged, has been very lame on both fore legs for about a month; has large splints and ringbones on both fore legs; has been fired on the ringbones; the splints show great tenderness on pressure.

I 8 th February I 897. Median neurectomy on both fore legs, under chloroform. Immediately after the operation there was no lameness. The wounds healed well, and the animal was sent to work about I 5 th March. Since then there has been no lameness, and the animal has worked regularly.

CASE 58.-Cab gelding, six years old when operated upon (18th February I897); has been lame for three months, and has a large splint, a ringbone, and a seedy toe. Median neurectomy was performed, but without any immediate beneficial result. On the 9th of March cxternal plantar neurectomy was performed, but the animal was still, on the $27^{\text {th }}$ of March, too lame for work. Since then, I have been unable to trace the case. 
CASE 59.-Cab mare, aged, had only been in the owner's possession a fortnight, and had been lame all the time; has a large exostosis (tender to pressure) under the knee, chronic tendinitis (probably largely due to the exostosis), and ringbones. The latter had been fired at some time or other.

Igth February I897. Median neurectomy under chloroform. There was no immediate improvement, but the animal eventually recovered about the $\mathrm{I} 2 \mathrm{th}$ of $\mathrm{March}$, and is at present doing regular work without showing any lameness.

CASE 60.-Cab gelding, aged, very lame on both fore legs. The lameness was diagnosed as being due to exostoses on the inside of each fetlock joint; ringbones were also present on each leg and a large splint on the off.

22nd February I 897. Median neurectomy was performed on both fore legs. After the operation there was a decided improvement, but the animal was still too lame to work, owing to the off fore leg; there was no perceptible lameness on the near fore.

I 5th March. External plantar neurectomy was performed on the off fore leg. As there was still no improvement, as a last resource the internal plantar nerve was divided, and subcutaneous periosteotomy performed on the exostosis under the knee. There was no improvement a fortnight later, and the animal was destroyed.

CASE 6I.-Cab mare, aged, had been very lame for six weeks; was suffering from lameness due to an exostosis on the inside of the fetlock joint. This had been fired without benefit.

9th March 1897 . Median neurectomy was performed. The animal never recovered sufficiently to do trotting work, and after being kept by the owner for about two months was sold to someone who could use it for walking work. Before the operation the mare was very lame even when walking slowly. Since then I have been unable to trace the case.

CASE 62.-Cab mare, aged, had been very lame for two months. There was present an exostosis on the inside of the fetlock and a ringbone. Lameness was diagnosed at the time as being due to the exostosis, which had already been fired and blistered without benefit.

II th March 1897. Median neurectomy under chloroform. There was no lameness after the operation. 'The wound healed without much trouble and the animal is still working; the owner states, however, that the mare occasionally falls lame after a severe trot, but that when worked quietly there is no return of the lameness.

CASE 63.-Cab gelding, aged, has been very lame for a month. Lameness was diagnosed as being due to chronically sprained tendons; the latter had been fired at some time or other.

I 2 th March I 897 . Median neurectomy was performed, and after the operation there was no lameness.

I 9 th March. Animal going well; no lameness. Since that date I have been unable to trace the case.

CASE 64.-Cab mare, aged, suffering from lameness due to chronically sprained tendons and an exostosis on the inside of the fetlock joint. These parts were severely fired and blistered about two months ago without benefit, the animal having only been able to do three days' work since, as she falls lame after being at work for a few hours. 
I2th March 1897. Median neurectomy was performed. Immediately after the operation lameness was hardly perceptible, and it passed off completely after trotting a short distance.

The mare was sent to work early in April and has been in regular work ever since without showing any more lameness.

CASE 65.-a hunter mare, aged, suffering from splints, exostosis on the inside of the fetlock, and ringbone. For the relief of the two latter double plantar neurectomy had already been tried after firing had failed, but the result was not a success. The conclusion arrived at by another veterinary surgeon (who was in charge of the case) and myself was that the lameness was probably almost entirely due to the mechanical interference caused by the exostosis at the fetlock joint; but, as there was a great desire to save the mare if possible, and there was decided tenderness over the region of the splints, median neurectomy was performed in order to alleviate this. Immediately after the operation there was indeed a perceptible improvement, but not sufficient to enable her to be sent to any work. The animal did not improve further, and has since been sold and lost sight of.

CASE 66.--Light van gelding, eight years old, very lame owing to the presence of splints on the inside of the cannon bone. Ringbones were also present. The animal had been lame for nine months, and had been fired and blistered on both places twice.

2nd March 1897. Median neurectomy was performed by request of the veterinary surgeon in charge of the case without any immediate improvement, but at the end of a fortnight the animal gradually got sound and was sent to work about 12 th April. Since then it has been working regularly, and has shown no return of the lameness.

CASE 67.-Hunter gelding, nine years old, acutely lame on the off fore leg. The animal could not bear to place any weight upon it, and went on three legs. This condition of lameness had been present for about six months, but for the past two years the patient had suffered from intermittent lameness (particularly marked after a hard day). There was a splint, exceedingly tender to pressure, extending underneath the tendons just below the knee; the tendons in this region were also slightly thickened and painful, and there was a small ringbone. The latter had been fired and blistered without permanent improvement being shown. After consultation with the veterinary surgeon in charge of the case, lameness was diagnosed as being due to pain produced by the pressure of the plantar nerve between the splint and the tendon.

2oth March I897. Median neurectomy was performed under chloroform. Immediately after the operation the animal trotted well, using the leg freely and only showing a lameness that would be perceptible to an expert.

2 Ist April. The wound had healed well, but there was still perceptible lameness after work.

26 th June I 897 . I saw the animal again, and found that there was now a distinct lameness; the animal had carried its owner through a cavalry training, but had shown lameness after duty. When warm and at work the lameness was not noticeable. After another consultation we decided to perform subcutaneous periosteotomy (and insert a seton) over the splint, and at the same time perform external 
plantar neurectomy. There was no immediate benefit, but about three weeks later there was no lameness at all, and since then the animal has passed through another cavalry training successfully.

CASE 68.-Light cart mare, aged, had been in present owner's possession about ten days and lame all the time. The animal had a very large splint (which appeared to be the cause of lameness) under the tendons; the latter were chronically thickened and tender on pressure in the region of the splint, and there was also a ringbone. Actual cautery had been applied at some time or other to the splint.

3rd April 1897. Median neurectomy under chloroform; there was a perceptible improvement after the operation. The wound healed well, and the animal recovered sufficiently to do slow work, in which it is at present employed.

CASE 69.--Van gelding, aged, had been very lame off and on for about twelve months, and was at present very lame. The animal has a ringbone, an exostosis on the inside of the fetlock, and thickened and contracted tendons. Double plantar neurectomy was performed about three weeks ago, in order to relieve the pain caused by the ringbone, but the result was unsuccessful.

6th April I897. Median neurectomy was performed as a last resource. Immediately after the operation the lameness was so slight as to be scarcely noticeable, and on 3 rd May even this had passed off completely, so that the animal was sent to work.

$4^{\text {th }}$ June. Animal worked well until a week ago; is now very lame on the same leg, the fetlock being swollen. Gelatinous degeneration is evidently taling place. Since that date I have been unable to trace the case, but I expect that the animal has been slaughtered.

CASE 70.-Cob, nine or ten years, was lame when bought about thirteen weeks ago; suffering from large exostoses on the inside and outside of the fetlock, the joint appearing almost anchylosed; there was also a thickened tendon. The animal had previously been fired, and had also had double plantar neurectomy performed without benefit. The case seemed a hopeless one, but, as a last resource, and thinking that perhaps the chronic tendinitis might account for a great deal of the lameness, median neurectomy was performed ( 13 th April 1897). After the operation there was a decided improvement, and the animal looked like being fit for walking work.

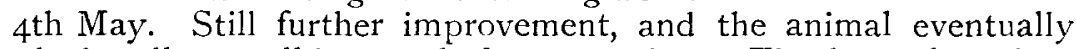
worked well at walking work for some time. The horse has since been sold, and I have been unable to trace it.

CASE 7 I.-Cab gelding, suffering from lameness due to neuromas at the seat of operation of a double plantar neurectomy which had been performed six months before; is now far too lame for work.

I 5 th April i 897 . Median neurectomy under cocaine. Lameness scarcely perceptible after the operation; the wound healed well, the remaining lameness passed off, and the animal has worked regularly ever since.

CASE 72.- Trap mare, about nine years old, very lame on the off fore leg, due to chronic tendinitis of the perforans and perforatus tendons. She had been lame for six months, and had been blistered without permanent benefit. This was the case operated upon before the West of England Veterinary Medical Association.

22nd April I897. Median neurectomy under the anæsthetic influ- 
ence of a mixture of eucaine and cocaine. Immediately after the operation the mare showed no lameness when trotted, and contınued to progress favourably for a fortnight, after which time, $\mathrm{Mr}$ Nelder informs me, she again became lame. At the present time $\mathrm{Mr}$ Nelder tells me that she is still not quite sound, but is sufficiently so to be at work in a butcher's cart occasionally.

CASE 73.-Cab mare, seven years old, has been very lame for three months. The lameness was diagnosed as being due to a large chain splint; there was also a ringbone present. About three weeks previously subcutaneous periosteotomy had been performed on the splint, and the ringbone had been fired, but without success, as the animal was still much too lame for work.

3oth April I\$97. Median neurectomy under cocaine. Immediately after the operation the lameness was very perceptibly diminished. On I4th May the animal was still too lame for work, but eventually it got all right, and was worked for a while, after which it was sold and lost sight of.

CASE 74.-Van mare, aged, suffering from lameness due to an exostosis under the knee and ringbone. The animal had been lame for fifteen weeks, and had been fired on the ringbone without any improvement resulting.

3rd May I897. Median neurectomy under cocaine. After the operation there was only slight lameness when trotting. The wound healed well, and the animal has been working regularly ever since. Occasionally she shows slight lameness, owing to a corn on the inside of the foot of the same leg, but when this is pared out the lameness passes off.

Rcmarks.-This case is of particular interest, as showing that a large amount of sensation is left in the structures on the inside of the foot.

CASE 75.-Cab mare, seven years, has been lame four weeks; very lame from a large exostosis on the inside of the cannon bone and ringbone.

I Ith May I897. Median neurectomy under cocaine; there was no improvement after the operation.

I 7 th May. Very lame; external plantar neurectomy was performed, but there was no improvement.

$25_{\text {th }}$ May. The animal was still very lame, and the owner was advised to have it destroyed.

CASE 76.-Cab gelding, aged, had been lame off and on for eight months; has a large splint and an exostosis on the inside of the fetlock joint; had been fired on the fetlock without improvement, and was now dead lame.

5th May I897. Median neurectomy under cocaine; immediately after the operation no lameness could be detected. When the patient, returned on the $13^{\text {th }}$ it was very lame again, and the owner stated that it had met with an accident to the fetlock (which was swollen) and then fallen acutely lame. On the Igth the animal was still very lame, and the owner decided to have it destroyed.

CASE 77.-Cab mare, aged, had been lame two months. The lameness was diagnosed as being due to chronic tendinitis; a ringbone was also present.

I7th May 1897. Median neurotomy under cocaine. Unfortunately 
the student who was operating, pricked one of the posterior radial veins and got a lot of hæmorrhage in consequence; when the nerve was cut the lower end was lost and could not be recovered (in order to remove a portion) without enlarging the wound; on account of the hæmorrhage we were unwilling to do this. There was no lameness after the operation.

25 th May. A large pocket of pus had formed, the leg being very much swollen and very sore. A seton was inserted in order to provide drainage, and removed on the 14th of June. The animal went to work on the 2 Ist of June, and has been working regularly ever since.

CASE 78.-Cab mare, nine or ten years old, has been lame on and off for two years. The lameness was due to chronic tendinitis and an exostosis inside the fetlock joint.

18th May I897. Median neurectomy under chloroform. There was severe lameness before the operation, but afterwards none could be detected except by an expert. The wound healed well; the animal has been turned out to grass ever since, and is not at all lame.

CASE 79.-Cab mare, aged, had been very lame on both fore legs (especially the off) for about a month. On the off leg there were exostoses on the inside of the cannon bone, slightly thickened tendons and a ringbone; on the near fore leg there were exostoses on the lower part of the cannon bone and a ringbone.

3rd June I 897. Median neurectomy was performed on both fore legs under chloroform. There was only a very slight lameness on the off fore after the operation. On the 25th of June this lameness was so slight as to be perceptible only to an expert, and the animal was sent to work. The owner worked the animal for a month, until financial difficulties caused it to be sold, since which time I have been unable to trace it further.

CASE 80.-Pony mare, aged, very lame on both fore legs, particularly the near one. There was a large ringbone on each leg, and a large splint under the knee of the fore.

Igth July I897. The animal was chloroformed, double plantar neurectomy being performed on the off fore leg, and median and external plantar neurectomies on the near fore. There was no lameness after the operation. The wounds healed well and the animal has been at regular work ever since.

CASE 8I.-Cart mare, six or seven years old, has been lame for some months; is suffering from chronically sprained and thichened tendons, splint, and ringbone. Actual cautery had been employed, but without beneficial result, about four months ago by the veterinary surgeon attending the case, and it was by his request that the operation was performed on the 2oth July 1897. There was no immediate improvement perceptible.

4th August. The animal walks better but still trots lame; external plantar neurectomy was suggested on account of the ringbone, but not consented to. The animal is decidedly improved and works well at walking work, although still showing lameness if trotted.

CASE 82.-Pony mare, had been very lame for several weeks; is now suffering from a ringbone and sprain of the check ligament. The ringbone had been fired and blistered four weeks before without benefit. 
I 5th July I897. Median neurectomy under chloroform. There was no improvement after the operation. A week later, however, the lameness was perceptibly less, and eventually it passed off. The animal has been in regular work ever since.

CASE 83.-Cab gelding, seven years old, had been in the present owner's possession eight months, and had been lame on and off all the time, sometimes on one fore leg and sometimes the other. On the near fore there was a splint about as large as a tangerine orange extending under the tendons, and an exostosis at the bottom of the radius. On the off fore there were splints on the outside and inside as large as walnuts. The animal was now lame on both fore, being worse on the near.

22nd July i 897. Median neurectomy on both fore legs. The animal was too much under the influence of chloroform afterwards to be able to trot. The wounds healed well, and the animal has been working well ever since without any return of the intermittent lameness.

CASE 84.-Cab mare, aged, has been lame off and on for ten weeks, and very lame for ten days or so. The lameness was diagnosed as being due to a large splint under the knee; the animal has also a ringbone.

6th August 1897. Median neurectomy under chloroform. Unfortunately, during the progress of the operation, the student operating pricked the posterior radial artery and vein. These were ligatured and the wound sutured. There was a great improvement noticeable after the operation. Since then the case has progressed well, there is no lameness, and the animal is back at regular work again.

CASE $85 .--$ Cab mare, six or seven years old, very lame from large exostoses on the inside and outside of the near fore leg.

In July subcutaneous periosteotomy was performed on each of these and setons inserted; these caused an improvement, but there was still severe lameness after the animal had been trotting for a while.

$9^{\text {th }}$ August I897. Median neurectomy under chloroform. There was a decided improvement after the operation. Eventually the wound healed, there was no lameness, and she worked regularly for about three weeks. At the end of three weeks she fell lame on the near hind, and rather than go to the expense of keeping her any longer the owner sold her.

CASE 86.-Cart mare, aged, suffering from a small splint, slight chronic thickening of the tendons, and a large ringbone. The latter had been fired without beneficial result.

3rd September I897. Median neurectomy under chloroform. There was no lameness after the operation. This case is still under treatment, but promises to make a good recovery.

CASE 87.--Cab gelding, about nine years old, had been in the present owner's possession about seven weeks, and had been lame off and on the whole time; was now very lame. The foot was contracted and had a concave sole (suspicions of navicular disease); there was also a small ringbone, and a very tender chain of small splints on the inside of the cannon bone. The splints had been fired at some time or other previously.

18th September 1897. Median neurectomy was performed, and there was no lameness perceptible after the operation. The case is still under treatment, and promises to make a good recovery. 
Summarising the above eighty-seven cases, I think that it will be acknowledged that the results are quite as satisfactory as were those which were published in the Journal last year. Altogether the operation has been performed ninety-seven times, as in ten cases both legs were operated upon. In no case up to the present have I been able to trace a ruptured tendon or sloughing of the hoof unless the external plantar nerve had also been divided. At least thirteen of the cases have now been at regular work for about eighteen months since the operation, whilst ten others have been working for more than twelve months.

I am more firmly convinced than before that for old-standing lameness, where due to splints, exostoses anywhere on the inside of the leg, chronically sprained, thickened, and painful tendons, or cases of that kind which cause pain by pressing on the adjacent nerve structures, after all other treatment has failed, median neurectomy is the operation which will often give the animal a new lease of life and usefulness.

That the whole of the sensation is not removed from the inside of the limb can readily be demonstrated by pricking the skin with a pin, and also by the fact of a corn, when very bad, causing lameness; also by Case 22 , in which a wound on the inside of the coronet, and Case 30, in which severe thrush, each caused temporary lameness.

That excision of the median nerve does not affect the healing of wounds in the parts below on the inside, is shown by those cases in which wounds were surgically or accidentally inflicted after the operation.

Case 24 , in which a neuroma formed on the median nerve, is worth a special note, as M. Pellerin, in his pamphlet on median neurectomy, draws especial attention to its rarity, as evidenced by the fact that he has never met with or heard of a case.

\section{EDITORIAL ARTICLES.}

\section{HEREDITY AND DISEASE.}

IT could not, without a sacrifice of candour, be said that the discussion on "heredity in its relations to the diseases of animals" at the recent annual meeting of the National Veterinary Association has shed much fresh light on that admittedly obscure subject. It would perhaps have been unreasonable to expect that the occasion would do much to elucidate what may be termed the mechanism of heredity, but one might not unnaturally have looked for some new facts and observations bearing on what is certainly the all-important question in connection with the subject of heredity, viz., What diseases of the lower animals ought to be classed as hereditary?

We cannot help thinking that an undue amount of attention was given both by the essayist and by some of those who took part in 